\title{
Establishment of Students Wisdom Learning Space based on Internet + Ronghua Zhang ${ }^{1, a}$ \\ ${ }^{1}$ Xi'an Peihua University, Xi'an, Shaanxi, 710125 \\ a email
}

Keywords: Internet+, Wisdom Learning Space, Construction

\begin{abstract}
Booming computer and Internet technology has greatly promoted the popularization of information technology and digital campus education, distance learning and online multimedia teaching is entering a new stage of development, online learning as a network carrier and teachers and teaching resources the main platform for interaction directly affects the quality of teaching Teaching. From Building Learning Network of the benefits of the reform of education, teachers, students bring departure, Importance of the college learning network construction analysis and recommendations learning network construction of university problems.
\end{abstract}

\section{Introduction}

Continuing education for higher education learning center position after the decision of their mandate, it should be at least around the university should have the "teaching, research, social services," the "teaching, social services." Defined from a technical point of view, the wisdom of learning centers is cloud computing, networking, mobile Internet, artificial intelligence and other information technology in the Integrated Learning Center, a comprehensive application, more flexible information infrastructure to support the broader Internet interoperability, a more thorough study situational awareness, a more intelligent application of data resources, more in-depth intelligent control, greener energy control. Different from the traditional university campus building in the campus of wisdom, wisdom, learning centers in the connotation and extension has its own characteristics. On the one hand, learning centers should follow their own position and division of labor to create their own wisdom campus learning centers to achieve the whole process of information; on the other hand, learning center and headquarters (school) are closely linked, it is reflected in the level of information to be understood as is the headquarters of the public cloud and private cloud learning centers achieve seamless. Therefore, the wisdom of learning centers in the system should include at least the wisdom of learning, wisdom, management, administrative wisdom, wisdom campus green, space intelligence, wisdom, health services into six parts.

Wisdom space. Space build environment, has substantial influence throughout the teaching, principals and leadership positions in UN's educational philosophy, can be arranged through the planning and design of physical learning environment, leading the school space and education reform and development. There Based on this, it is necessary to study the space center for the overall planning, reasonable construction types and forms of teaching with suitable education programs. By pre-construction phase of spatial planning, spatial planning led curriculum development, to lead teaching innovation, teaching mode, promote administrative reform, and the ability to expand the relationship to serve the surrounding communities. The management wisdom. In all aspects of the education service center, carding process of logistical requirements, and together with the design and evaluation services, encapsulates the Learning Center App in classroom management, to achieve a key appointment cleaning, ordering, maintenance, security fast response and other services. Administrative wisdom. In the original Learning Center personnel management, financial management, administration, educational administration and other conventional information systems based on Internet + according to the concept of interoperability on the basis of data on the establishment of service-window, multi-terminal fusion manner the transformation of the original there are business and achieve learning center to provide space for the teaching staff to apply dynamic, all kinds of teaching project costing and input-output analysis, performance management, learning center within the management of all types of administrative 
services office for approval. Green wisdom. IntelliSense Learning Center functioning of each space energy effective regulation to ensure intelligent management center energy consumption. Wisdom Learning. Learning centers around the various types of space design appropriate learning environment, mobile learning, and different kinds of learning modes (such as collaborative learning, inquiry-based learning, etc.) support, as well as classroom teaching and teaching seamless cloud platform, and constantly create efficient classroom everywhere learning environment. Wisdom health services. Around the sensing device to the Learning Center staff and other health data collected temperature monitoring, data centers of the space environment to provide real-time monitoring and intelligent management, under the premise of ensuring safety metrics to optimize the environment as much as possible, to provide intelligence to all types of users learning center of environmental management services.

\section{The Importance of University Learning Network Construction}

Learners two-step process, the first step is the transfer of knowledge, the second step is to build the learner and flexible application of knowledge. That is to expand knowledge of sublimation, the traditional mode of teaching through teacher face to face lectures complete knowledge transfer. After-school students do exercises or practice to achieve job expansion sublimation due learner characteristics, including pre-school level of knowledge, cognitive ability, cognitive structure and learning style. There are individual differences. Even teachers adequate learner analysis. Only teaching is for the majority of learners. Difficult in the classroom is limited period of time to take care of all learners. Thus contradictions group teaching and individual differences is always difficult to solve in the traditional teaching process, knowledge transfer and sublimation process under the class of the same problems. Due to inconvenient to get timely help teachers and peers. Problems encountered can not be solved in time. Prone to emotional weariness. Effect of active learning, in order to solve problems in traditional teaching model. Scholars working on teaching mode reform, along with the development of information technology. Education efforts through information technology to promote educational reform. Such as information technology-assisted teaching from. The integration of information technology and curriculum. Then the depth of information technology and curriculum integration. Its essence is at different stages of Blended Learning online and offline, according to the purpose of school education development needs, the face to face teaching and online teaching organic combination. In this mode of teaching, online teaching should not only play a supporting role, but Lectures organic composition. The building Learning Network is a prerequisite for network instruction. On the basis of Blended Learning on-year there has been teaching and individual differences can be resolved this contradiction groups flipped classroom teaching. Flipped classroom is the core concept overturned traditional teaching mode, the first class, students in the class teachers use video and related materials to learn, teachers to view student learning in the management platform, summed students encounter in the learning process issue \# classroom time is based on students' learning problems encountered in the process to explain, to solve the problem, the concept of deepening participation and cooperation learning. But both the former class teacher to collect, collate, make videos, or students learning, the learning process interact with each other, teachers statistical analysis of student learning are inseparable unified platform, while the Ministry of Education Learning Network may flipped classroom to make up for deficiencies in the process of implementation. Since flipped classroom produced since many schools and educational institutions use this mode, and achieved optimum results. At present, many schools are adopting the flipped classroom model, expected to be a turning point in the flipped classroom teaching. Construction Learning Network will be flipped classroom embodiment provides a necessary virtual digital learning environment, or is a necessary condition for the implementation of the flipped classroom, it can be said that the construction of Learning Network will effectively promote the implementation of educational reform. 


\section{Strategies to Improve and Enhance Learning Space}

Learning Network as a new teaching platform and application development requires a certain period of time, the development of e-learning space is divided into two parts, hardware and software. In terms of hardware, the first is to improve the level of its hardware platform and corresponding network facilities to enable it to cope with larger data load to handle more users and information resources to provide more high-speed download speed; second is to increase the digital campus building, in particular digital multimedia classroom building to enable students to access online learning space greatly reduce the cost. Software, first, the school should actively encourage teachers to carry out teaching and learning space on network activities, a part of some achievement and teachers to give financial and technical incentives to enhance the speed of advancement of learning space; second, Instructor We should actively guide students to use e-learning space, as much as possible of the learning task and learning network linked, so that students quickly adapt learning network learning environment, improve learning efficiency.

Use Learning Network classrooms from various professions, in addition to individual professional, other professional classroom need to be appropriate. The training consists of two aspects: one is the level of training of educational technology, the other is for the network applied learning training space. Henan Learning Network pilot process for colleges and universities training teachers for space applications, but training on educational technology ability of teachers needed to be but not enough attention. How in the Learning Network Environment instructional design, develop teaching strategies and teaching methods choose to focus on training, so that teachers will not only use but also to use well the corresponding function module. Learner as the subject of online teaching, technical level of their education is directly related to the acquisition of knowledge, process knowledge and ability to use e-learning tools in Learning Network environment. Different students learning cognitive level are quite different, some students can not even use a good variety of network tools, they will encounter greater obstacles in the process of teaching-learning space. Improve students' learning level space applications could start from the following aspects, first, educational technology and e-learning training courses in space freshmen, enhancing the overall skill level of the learners, the second is specifically provided in the school website or in the Learning Network the corresponding plate, provide tutorials and help for autonomous learning convenience.

Theory to practice guiding significance, developed under the Learning Network Environment teachers design teaching content and teaching strategies of online teaching is inseparable from solid theoretical foundation. With appropriate support learning theory, teachers can better teaching, in order to better carry out teaching activities based on the student's learning needs. Learners to enhance the theoretical level, in favor of understanding the role of student learning space right, and continue to enhance their motivation to learn, the better spatial learning and classroom learning together, enhance their learning efficiency. Enhance the theoretical level of teachers and students can carry out the following: In the Learning Network education and technology training process, the network focus its teaching theory, the theory of education Learning Network, to enhance the theoretical level of teachers; network teaching process, teachers should provide students explain the relevant theories of learning and learning strategies so that students will learn everyday and theoretical integration.

\section{Conclusion}

The rapid development of computer network and information technology for the realization of educational information provides important protection, e-learning is an important aspect of information technology in education, online learning is a learning network carrier. Network Teaching in Henan College must have been carried out time and made some achievements, most colleges and universities have their own e-learning platform, but due to various reasons, the support of teachers and teaching is not ideal. This article first analyzes the characteristics of domestic and 
foreign research different network learning platform, based on constructivist learning theory and humanism learning theory, through field research, literature analysis, interviews and document survey and other research methods, Henan features of University learning network for analysis. Through field research and surveys on the current situation in Henan Academic Learning Network to promote the situation of teachers and students and applications Learning Network conducted a survey and analysis of multi-angle, explore the main factors affecting the Henan university teachers and students to use e-learning space, learning resources, teaching space and fit, as well as the perspective of teachers and students of University support for the learning network and other aspects of starting, reasonable and effective measures to enhance the effectiveness of the application.

\section{Acknowledgements}

This paper is 2016 Xi'an Peihua University Reform Key Issues teaching patterns innovation of advertising major under the teaching concept of OBE. The phased research result (item number PHZ1601).

\section{References}

[1] Pavlo Antonenko, Serkan Toy, Dale Niederhauser Modular Object-Oriented Dynamic Learning Environment: What Open Source Has to Offer [J]. Association for Educational Communications and Technology, 2004, (27): 41-43.

[2] Matthew Perkins, Jay pfaffman. Using a Course Management System to improve Classroom Communication [J]. Science Teacher, 2006, (33): 53-57.

[3] Souad El Harrassi, Miehel Labour.Increasing Inter operability of E-learning Contenting Moodle with in a Franco-Arabo Edueative Context [J]. Educational Technology Magazine: The Magazine for Managers of Change in Education, 2010, (32): 68- 73.

[4] Cao Liangliang, Yuan Keding. Online learners explore behavioral characteristics [J]. China Distance Education, 2012, (03): 56-61.

[5] Zhang Chao, Zhu Zhiting. Study the topology of the online learner asynchronous interaction An Analysis Based on Complex Network Model [J]. Educational, 2009, (02): 59-63. 